\title{
Comparisons of the Nottingham Health Profile and the SF-36 health survey for the assessment of quality of life in individuals with chronic stroke
}

\author{
Comparação do perfil de saúde de Nottingham e SF-36 na avaliação da \\ qualidade de vida de indivíduos com acidente vascular encefálico crônico
}

Dinalva L. Cabral', Glória E. C. Laurentino', Caroline G. Damascena', Christina D. C. M. Faria², Priscilla G. Melo', Luci F. Teixeira-Salmela²

\begin{abstract}
Background: Appropriate instruments for the assessment of health-related quality of life (HRQOL) domains are useful for planning therapeutic interventions for individuals with stroke. The generic quality of life (QOL) instruments, Short Form Health Survey-36 (SF-36) and Nottingham Health Profile (NHP), have been frequently employed in the Brazilian literature. However, the literature is still scarce regarding their psychometric properties when applied to stroke individuals. Objectives: To compare the Brazilian versions of the SF-36 and the NHP to verify which had better psychometric properties for the assessment of HRQOL in 120 individuals with chronic stroke. Method: Spearman correlation coefficients were calculated to examine the comparable domains and total scores of the SF-36 and the NPH; Cronbach's alpha coefficients, to evaluate internal consistency; intra-class correlation coefficients, to assess reliability; and Bland-Altman plots, to assess the levels of agreement, with a significance level of $5 \%$. Results: Significant positive associations were observed between the common domains and the total scores of the SF-36 and the NPH. Ceiling effects were more frequent for the NPH. The total scores of both instruments achieved adequate reliability levels, and the agreement levels were within the normal limits in 95\% of the cases. Conclusions: The SF-36 and the NPH were shown to measure similar constructs and proved to be useful measures for the assessment of QOL of chronic stroke subjects. However, the SF-36 yielded better results and appeared to be more appropriate.
\end{abstract}

Keywords: Stroke; quality of life; Nottingham Health Profile; Short-Form Health Survey-36; psychometric properties; rehabilitation.

\section{Resumo}

Contextualização: Instrumentos adequados para avaliar os vários domínios da qualidade de vida (QV) relacionada à saúde (QVRS) constituem uma importante abordagem para o planejamento terapêutico e, assim, melhor assistir os indivíduos acometidos pelo acidente vascular encefálico (AVE). Na literatura brasileira, os instrumentos genéricos Formulário Abreviado de Avaliação de Saúde 36 (SF-36) e Perfil de Saúde de Nottingham (PSN) têm sido bastante empregados, entretanto, ainda existem lacunas relativas às suas propriedades psicométricas quando aplicados em indivíduos pós-AVE. Objetivos: Comparar as versões brasileiras dos instrumentos SF-36 e PSN e verificar qual deles apresenta melhores propriedades psicométricas para avaliar a QVRS de 120 indivíduos na fase crônica pós-AVE. Método: A comparação entre os domínios comuns e escores totais do SF-36 e PSN foi realizada pelo Coeficiente de Correlação de Spearman, Coeficiente Alpha de Cronbach, para avaliar a consistência interna; Coeficiente de Correlação Intraclasse, para mensurar a confiabilidade, e o teste de plotagem Bland-Altman para a concordância, com nível de significância de 5\% em todos os cálculos. Resultados: Todas as correlações entre o SF-36 e o PSN, escores totais e domínios comuns, foram positivas e estatisticamente significativas. Observou-se maior frequência de efeito teto no PSN. Os escores totais de ambos atingiram níveis adequados de confiabilidade, e os níveis de concordância estavam dentro dos limites normais em 95\% dos casos. Conclusões: SF-36 e PSN mensuraram constructos semelhantes e demonstraram ser úteis para avaliar QV de indivíduos pós-AVE crônico. No entanto, o SF-36 proporcionou melhores resultados e pareceu ser mais apropriado.

Palavras-chave: acidente vascular encefálico; qualidade de vida; Perfil de Saúde de Nottingham; Formulário Abreviado de Avaliação em Saúde 36; propriedades psicométricas; reabilitação.

Received: 11/16/2011 - Revised: 02/29/2012 - Accepted: 03/20/2012

'Physical Therapy Department, Universidade Federal de Pernambuco (UFPE), Recife, PE, Brazi

2Physical Therapy Department, Universidade Federal de Minas Gerais (UFMG), Belo Horizonte, MG, Brazil

Correspondence to: Glória Elizabeth Carneiro Laurentino, Departamento de Fisioterapia, Universidade Federal de Pernambuco, Avenida Professor Jornalista Aníbal Fernandes, S/N,

Cidade Universitária, CEP 50740-560, Recife, PE, Brasil, e-mail: gloria_laurentino@yahoo.com.br; gloriaecl@ufpe.br 


\section{Introduction $: \therefore$.}

According to the World Health Organization (WHO), in 2001 more than 20 million individuals experienced stroke ${ }^{1}$, making this health condition the third leading cause of death in industrialized countries and the leading cause of chronic disability for adults ${ }^{2}$ worldwide. Population-based studies carried out in Brazilian communities have shown that 137 to 168 new cases of stroke per 100,000 inhabitants per year have been observed in the last three decades ${ }^{3-5}$. This high incidence, combined with reduced mortality due to technological advances, has led to high numbers of individuals with functional, psychological, social, and physical deficits ${ }^{6}$.

Quality of life (QOL) assessment encompasses various aspects related to psychological, social, and physical wellbeing ${ }^{7}$. The instruments designed to assess health-related QOL (HRQOL) are classified as generic and specific. The generic instruments have the advantage of allowing simultaneous assessments of several areas for all populations and allowing comparisons between individuals with different health conditions. The disadvantage is that they may not show changes in certain specific aspects ${ }^{8,9}$.

Although the literature has shown several instruments already validated for the assessment of HRQOL, it is important that their psychometric properties be evaluated so that the choice of the instrument can be based on evidence that the measures are valid for the studied populations ${ }^{10}$. In Brazil, most of the studies that assessed HRQOL in stroke patients used generic instruments, such as the Short Form Health Survey-36 $(\mathrm{SF}-36)^{11,12}$ and the Nottingham Health Profile (NHP) ${ }^{13}$. Both are simple, easy-to-understand tools that can be administered in a short time, which demonstrates their robust clinical applicability ${ }^{14}$. Moreover, the SF-36 was indicated by the Agency for Healthcare Research and Quality as one of the best tools for the assessment of stroke patients ${ }^{15}$ and is considered to be the gold standard in health-related studies ${ }^{7,16}$.

Despite some similarities between the SF-36 and the NHP, there are significant differences in terms of response to questions, scoring, and domains, e.g. the domains general health state and emotional and physical limitations that are only assessed in the SF-36 and the sleep domain evaluated only by the $\mathrm{NHP}^{14}$. These peculiarities have motivated an increasing number of researchers to investigate the suitability of generic HRQOL instruments for patients with various chronic diseases, such as stroke $\mathrm{e}^{17}$. Therefore, the present study aimed to compare the Brazilian versions of the SF-36 and the NHP to determine which instrument has the best psychometric properties and which one is the most suitable for the assessment of perceived QOL in chronic stroke individuals.

\section{Method : :}

\section{Participants}

This study was carried out with 120 participants with stroke recruited in two large Brazilian cities: Recife, $\mathrm{PE}(n=74)$ and Belo Horizonte, MG, Brazil ( $n=46)$ from October 2009 to June 2010. To be included in the study, the participants were required to have a diagnosis of stroke for more than six months, be over 20 years old, and have no cognitive deficits, as determined by the cut-off scores of the Brazilian version of the Mini-mental State Examination (MMSE) ${ }^{18}$. Individuals with hearing and/or speech impairments and those who reported any history that could jeopardize their QOL were excluded.

For the reliability assessments, a pilot study was performed with a group of 30 individuals with chronic stroke to calculate the sample size based on the mean estimates and a 95\% confidence interval. Thus, assuming a maximum error of 10 points, the sample size was estimated to be at least 53 individuals for the NHP and 74 for SF-36. Therefore, to evaluate the test-retest and inter-rater reliabilities, the sample was composed of 74 individuals selected from seven community health centers of the city of Recife, PE, Brazil.

For the comparative study of the common areas and total scores of the SF-36 and NHP, 120 individuals with chronic stroke participated. From the obtained data, it was confirmed that the sample size was sufficient to estimate the means in each of the domains of the SF-36 and NHP with a 95\% confidence interval and a maximum error of six points.

The study was approved by the Research Ethics Committees of Agamemnon Magalhães Hospital, Recife, PE, Brazil (protocol number 316/2009, 0073.0.236.172-09) and Universidade Federal de Minas Gerais (UFMG), Belo Horizonte, MG, Brazil (protocol number 0492.0.203.172-09). The participants signed an informed consent form to take part in the study.

\section{Instruments and procedures}

Information regarding the procedures and objectives of the study was provided to all participants, who were then asked to sign a consent form approved by the ethics committee of the institution. During home visits, the participants were interviewed individually. The interviews lasted approximately 40 minutes and included demographic and clinical information regarding gender, age, time since the onset of stroke, and the affected side. After that, each participant answered the items of the SF-36 and NHP. The order of administration of the instruments was randomly chosen by lot by each participant. 
The SF-36 was translated into Portuguese and validated by Ciconelli et al. ${ }^{16}$. It is a generic 36-item QOL tool that covers eight dimensions of health, including limitations in physical functioning, common daily activities, social functioning related to health problems, and vitality, and it also includes a global evaluation of health. Each dimension is scored on a scale of 0 to 100, with higher scores indicating better health. The number of possible responses per item ranges from two to six.

The NHP is a widely used generic tool that was translated and adapted to the Brazilian population by Teixeira-Salmela et al. ${ }^{13}$. It contains 38 yes/no statements divided into six domains: energy levels, physical abilities, pain, emotional reactions, sleep, and social interactions. Each affirmative response is worth one point and each negative response is worth zero points, for a maximum score of 38 points $^{13}$.

To facilitate comparisons, the dimensions of these two instruments were normalized using linear transformations to recode scores from zero (poor health) to 100 (perfect health) ${ }^{19}$. Although the SF-36 and NHP are self-administered tools, they were applied by trained examiners due to possible heterogeneity regarding the degrees of education between the selected subjects, following the recommendations of Teixeira-Salmela et al. ${ }^{13}$. To evaluate the inter-rater reliability (reproducibility), the SF-36 and NHP were applied by two independent examiners, who did not share their data. To assess the test-retest reliability (repeatability), one examiner applied the instruments on two different occasions at least seven days apart. The order of application in the second assessment was the same as the one adopted during the first visit. During the evaluations, individuals who reported facts which could have affected their QOL, such as the occurrence of new episodes of stroke, and the loss of a loved one, were automatically excluded.

\section{Statistical analysis}

Descriptive statistics (means and standard deviations and confidence intervals) were calculated for sample characterization purposes. Spearman's correlation coefficients were calculated to evaluate the degrees of associations between the SF-36 and the NHP, taking into consideration only the total scores and those related to the common domains of the SF-36 (vitality, pain, mental health, social, and functional capacities) with those of the NHP (energy levels, pain, emotional reactions, social interactions, and physical abilities).

For each domain of the SF-36 and the NHP, the floor and ceiling effects were calculated based on the percentage of participants who obtained the lowest scores (zero) and the highest scores (100). According to McHorney et al. ${ }^{20}$, the existence of these properties can only be taken into consideration when the values exceed $20 \%$.
Intra-class correlation coefficients (ICC) were employed for the test-retest and inter-rater reliability assessments. ICC values ranged from zero to one and, in this study, they were classified as: unacceptable $(\leq 0.70)$, acceptable (between 0.71 and $0.79)$, very good (between 0.80 and 0.89$)$, and excellent $(\geq 0.90)$.

To assess internal consistency, Cronbach's alpha $(\alpha)$ was employed. This index is commonly used to verify the internal consistency of a group of items. The values range from zero to one and can be classified as very good $(>0.90)$, good (between 0.80 and 0.90$)$, reasonable $(0.70$ to $<0.80)$, low $(0.60$ to $<0.70)$, and unacceptable $(<0.60)$.

The test-retest and inter-rater agreements for the total scores of the SF-36 and NHP were evaluated using BlandAltman plots. Scatter plots were constructed to show the individual differences on the y-axis, according to observed means for the $\mathrm{x}$-axis. It was expected that by applying the same instruments on the two occasions with the same individuals in similar situations, the average should approach zero. All analyses were performed with the software Statistical Package for Social Sciences (SPSS) version 13.0 and Prism, with a significance level of $95 \%$.

\section{Results $: \because$.}

Initially, 184 individuals were contacted, however 58 (31.5\%) did not meet the inclusion criteria (Figure 1). Of the 126 recruited participants, six dropped out, leaving 120 participants: $55.8 \%$ women, with a mean age of $60.7 \pm 11.8$ years, a mean time since the onset of stroke of $6.5 \pm 5.9$ years, and a slight predominance of right hemiparesis (53.3\%). For the assessment of testretest and inter-rater reliability and agreement, the data from 74 participants were included.

Table 1 shows the results of the comparisons between the common domains and the total scores for the SF-36 and NHP of 120 participants. Both the SF-36 and NHP demonstrated an average of total scores above 50 points. Domains with mean scores below 50 were observed only for the SF-36:

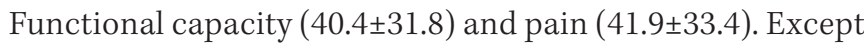
for the social functioning domain, the scores in all the other domains, as well as the total scores were higher for the NHP (66.1 \pm 22.3$)$.

All correlations related to the total scores $(r=0.80, \mathrm{p}<0.01)$, and those related to the common domains were positive and statistically significant. The highest correlations were observed between the functional capacity and physical ability domains ( $r=0.82, \mathrm{p}<0.01$ ), whereas the lowest ones were between the social functioning and social interaction domains $(r=0.43, \mathrm{p}<0.01)$. It was also observed that the ceiling effects were more frequent for the NHP ( $80 \%$ of the domains) and the absence of floor 


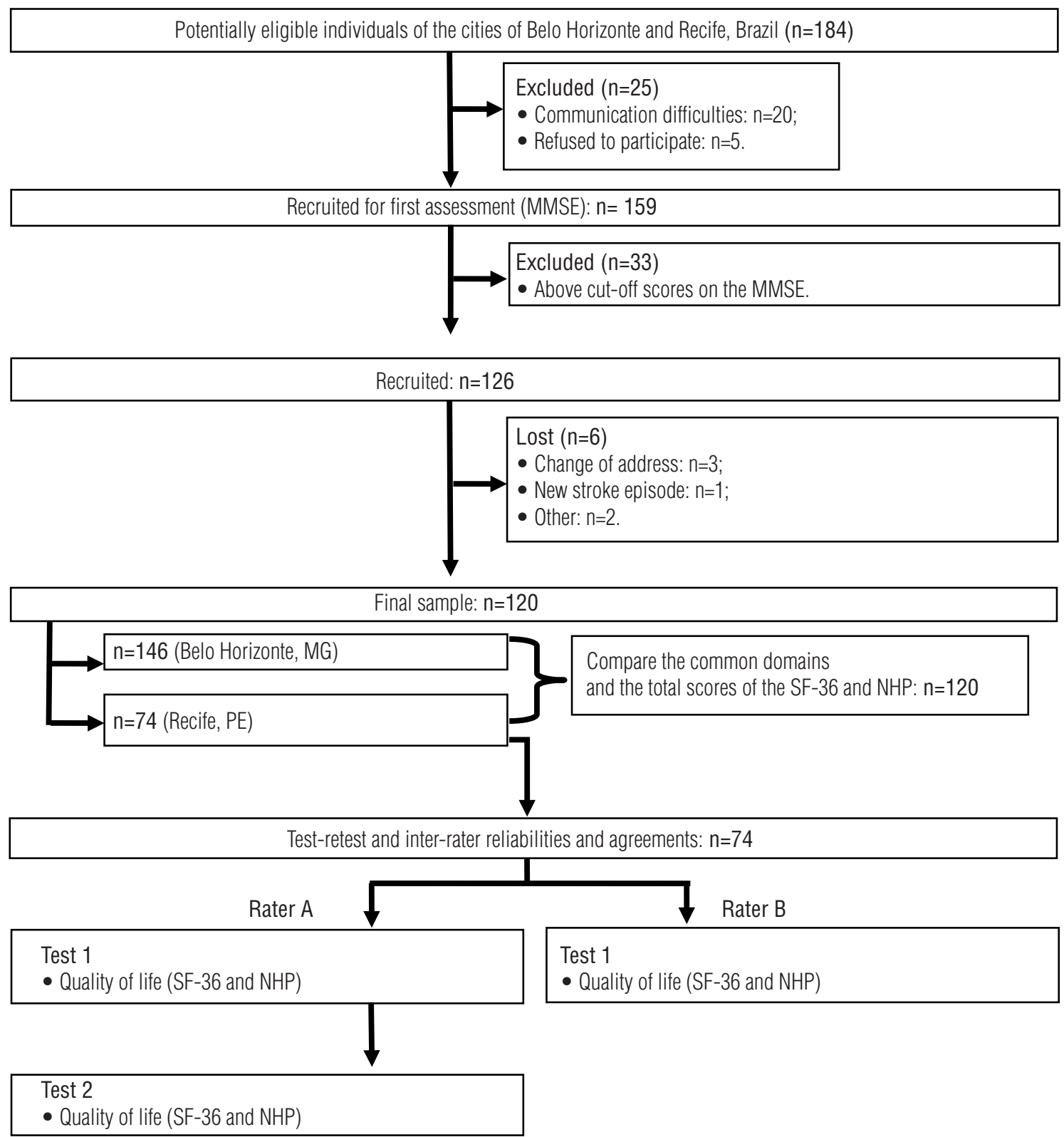

MMSE=Mini Mental State Examination; SF-36=Short Form Health Survey-36; NHP=Nottingham Health Profile.

Figure 1. Flow diagram of the study.

effects for both instruments. When analyzing the set of domains of each instrument, the internal consistency values were $\alpha=0.82$ and $\alpha=0.79$ for the NHP and the SF-36, respectively (Table 1). Regarding reliability, the total scores of the SF-36 and NHP obtained ICC values of 0.89 and 0.96 for the test-retest and of 0.89 and 0.92 for the inter-rater values, respectively $(\mathrm{p}<0.01)$ (Table 2$)$.

The Bland-Altman plots verified the agreement between the SF-36 and NHP mean total scores in relation to the testretest and inter-rater scores (Figures 2 and 3). For the SF36 , test-retest limits of agreement ranged between 27.3 and 26.9 points and the inter-rater limits between -26.9 to 28.9 (Figure 2). For the NHP, the test-retest limits of agreement ranged from - 13.8 to 23.4 points and inter-rater values between -23.4 and 13.8 points (Figure 3 ).

\section{Discussion $: \because$.}

Considering participant characteristics, the profile was similar to that of other investigations conducted in Brazil ${ }^{21-23}$, in which the occurrence of stroke was more frequent among individuals over 60 years of age ${ }^{21,22}$ and with a slight predominance of women ${ }^{23}$. According to Cavalcante et al. ${ }^{23}$, the predominance of women affected by stroke may have been related 
Table 1. Comparisons between the common domains and the total scores of the SF-36 and the NHP in individuals with chronic stroke ( $\mathrm{n}=120$ ).

\begin{tabular}{|c|c|c|c|c|c|c|}
\hline Domain & & Mean (SD) & Ceiling effect & Floor effect & $r$ & $p$-value \\
\hline \multirow{2}{*}{ Vitality/ energy levels } & SF-36 & $57.8(28.8)$ & 5.8 & 6.7 & 0.47 & \\
\hline & NHP & $72.8(32.6)$ & 50.0 & 8.3 & & $<0.01$ \\
\hline \multirow{2}{*}{ Pain/pain } & SF-36 & $41.9(33.4)$ & 13.3 & 9.2 & 0.63 & \\
\hline & NHP & $71.2(31.4)$ & 30.8 & 5.8 & & $<0.01$ \\
\hline \multirow{2}{*}{$\begin{array}{l}\text { Mental health/emotional } \\
\text { reactions }\end{array}$} & SF-36 & $62.3(26.3)$ & 7.5 & 4.2 & 0.70 & \\
\hline & NHP & $66.5(30.1)$ & 22.5 & 3.3 & & $<0.01$ \\
\hline \multirow{2}{*}{$\begin{array}{l}\text { Social functioning/social } \\
\text { interactions }\end{array}$} & SF-36 & 72.5 (31.2) & 44.2 & 4.2 & 0.43 & \\
\hline & NHP & $65.3(30.1)$ & 25.8 & 5.0 & & $<0.01$ \\
\hline \multirow{2}{*}{$\begin{array}{l}\text { Functional capacity/physical } \\
\text { ability }\end{array}$} & SF-36 & $40.4(31.8)$ & 3.3 & 8.3 & 0.82 & \\
\hline & NHP & $54.5(27.8)$ & 9.2 & 1.7 & & $<0.01$ \\
\hline \multirow{2}{*}{ Total } & SF-36 & $58.8(22.3)$ & 0.0 & 0.0 & 0.80 & \\
\hline & NHP & $66.1(22.3)$ & 0.8 & 0.0 & & $<0.01$ \\
\hline \multirow{2}{*}{ Cronbach's $\alpha$} & SF-36 & 0.79 & ---- & ---- & --- & ---- \\
\hline & NHP & 0.82 & ---- & ---- & --- & ---- \\
\hline
\end{tabular}

NHP=Nottingham Health Profile; SF-36=Short Form Health Survey-36; SD=standard deviation; Ceiling effects=percentage of individuals who achieved the highest possible scores; Floor effects=percentage of individuals who achieved the lowest possible scores; $p=$ Spearman correlation coefficients; $\alpha=C$ Conbach's alpha.

to age, because nationally women live longer than men. Therefore, it is believed that cardiovascular and metabolic changes associated with the aging process may increase the risks for the development of stroke ${ }^{23}$.

The results of the present study demonstrated a positive trend regarding perceived health of the evaluated individuals. Taking into account that the sample was composed of individuals with chronic stroke, these findings may be related to recovery of physical and cognitive functions. According to Rabelo and $\mathrm{Néri}^{24}$, recovery tends to reach stabilization within six months after the occurrence of stroke and allows the individuals to learn how to cope with their disabilities, and this fact appeared to have positive effects on HRQOL ${ }^{25}$.

The functional capacity and pain domains, both assessed by the SF-36, were the ones most negatively affected by stroke. Kong and Yang ${ }^{26}$ compared the HRQOL in a group of chronic stroke individuals undergoing rehabilitation in the general population. They observed that the scores of some domains were similar between groups, except for the functional capacities, in which the stroke individuals scored lower. It should be noted that this domain specifically evaluates the performance of activities with high physical demands, such as running, lifting heavy objects, and climbing stairs, which most individuals with this condition have difficulty performing ${ }^{26}$. For the NHP, none of the domains had low health perceptions, which may indicate that this instrument has low discriminatory capacity.

According to Lima et al. ${ }^{21}$, generic instruments may underestimate the impact of stroke, since they are less sensitive to the effects of specific health conditions. Therefore, there is not a single instrument capable of assessing all health situations and the choice of an instrument should be associated with the objectives of the study, language accessibility, and cultural context ${ }^{9}$.
Table 2. Test-retest and inter-rater reliability coefficients for the SF-36 and NHP total scores of individuals with chronic stroke $(n=74)$.

\begin{tabular}{lccc}
\hline \multirow{2}{*}{ Reliability } & \multicolumn{2}{c}{ Total Scores } & \multirow{2}{*}{ p-value } \\
\cline { 2 - 3 } & SF-36 & NHP & \\
\cline { 2 - 3 } & ICC $(95 \% \mathrm{CI})$ & ICC $(95 \% \mathrm{CI})$ & \\
\hline Test-retest (rater A) & $0.89(0.83-0.93)$ & $0.96(0.93-0.97)$ & $<0.01$ \\
\hline $\begin{array}{l}\text { Intra-rater } \\
\text { (raters A and B) }\end{array}$ & $0.89(0.83-0.93)$ & $0.92(0.88-0.95)$ & $<0.01$ \\
\hline
\end{tabular}

SF-36=Short Form Health Survey-36; NHP=Nottingham Health Profile; ICC=intra-class correlation coefficients; $\mathrm{Cl}=$ confidence intervals.

The present study compared two generic QOL instruments with different origins, structures, and extensions. Nonetheless, statistically significant and positive correlations were found between both the total and the common domain scores, suggesting that they appeared to measure similar constructs. Falcoz et al..$^{14}$ found similar correlations between the domains of physical functioning in the SF-36 and physical ability in the NHP ( $r=0.57)$ with cardiac patients before and after surgery. In contrast, Prieto et al..$^{27}$ reported low correlations between social functioning and social interaction domains in patients with chronic pain and chronic obstructive pulmonary disease. The authors reported better perceptions of QOL for the NHP social interaction domain and lower ones for the SF-36 social functioning domain. The present study found trends towards good health perceptions in both domains.

The social interaction domain of the NHP includes items that emphasize psychological aspects, while the social functioning domain of the SF-36 is comprised of items related to both psychological and physical aspects. The fact that the participants in the present study demonstrated better perceptions in these domains and poorer perceptions in those related to functional and physical abilities may suggest that the social lives of these individuals had a greater influence from psychological factors. 

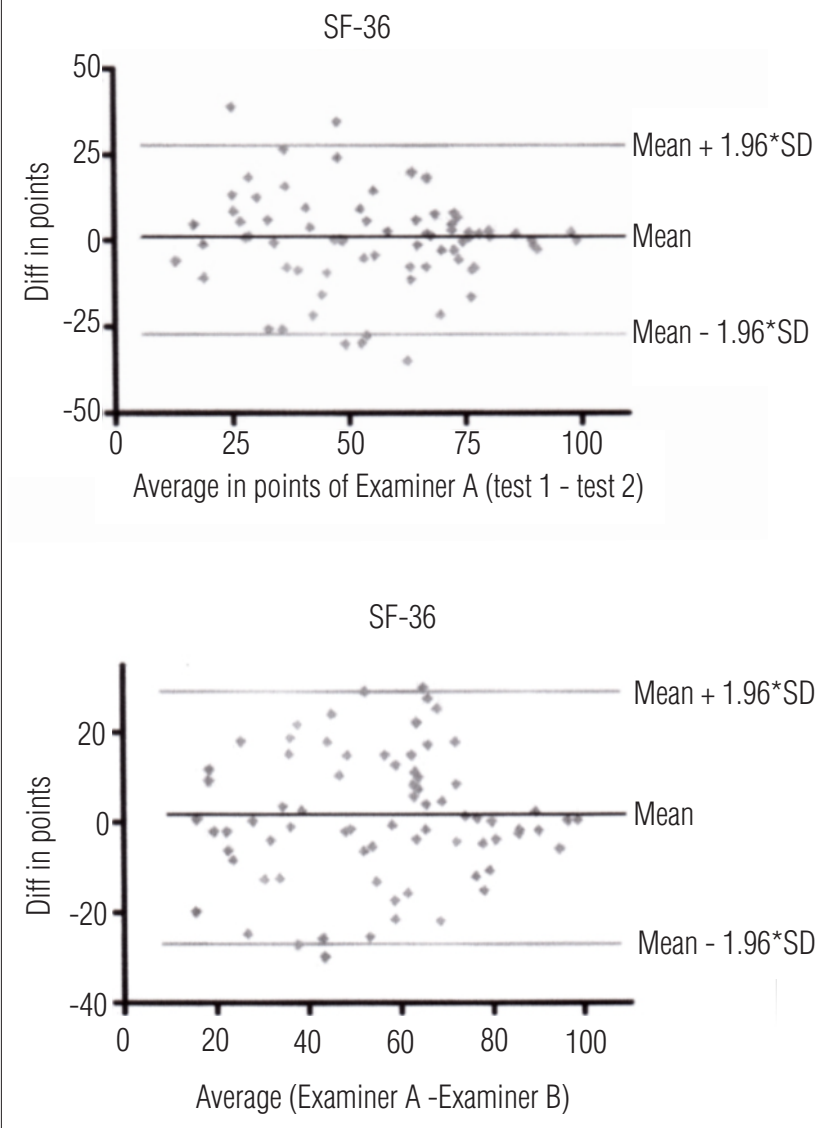

Figure 2. The Bland-Altman plots verified the agreement of the SF-36 mean total score in relation to the test-retest and inter-rater score in individuals poststroke ( $n=74)$, Recife, PE, Brazil, 2010.

For both instruments, the lack of floor effects demonstrated that their domains did not include very complex items, but ceiling effects were observed. Teixeira-Salmela et al. ${ }^{13}$ applied the NHP to 170 community-dwelling elderly individuals, 15 elderly individuals with Parkinson's disease, and 30 chronic stroke individuals. The authors reported that the major limitation of this instrument was the inability to discriminate between individuals, since it included some very easy items. Therefore, the presence of high scores should be interpreted with caution as it did not mean that all individuals had excellent QOL. The authors also pointed out that some items were related to basic skills that all participants were able to perform ${ }^{13}$.

The fact that the frequency of ceiling effects was much higher for the NHP could be explained by the dichotomy of the responses, while the SF-36 allows a greater number of possible responses. Moreover, the NHP has fewer items in each of the domains, which also increases the likelihood of ceiling or floor effects ${ }^{15}$. However, it should be considered that the dichotomous responses and the fewer number of items of the NHP

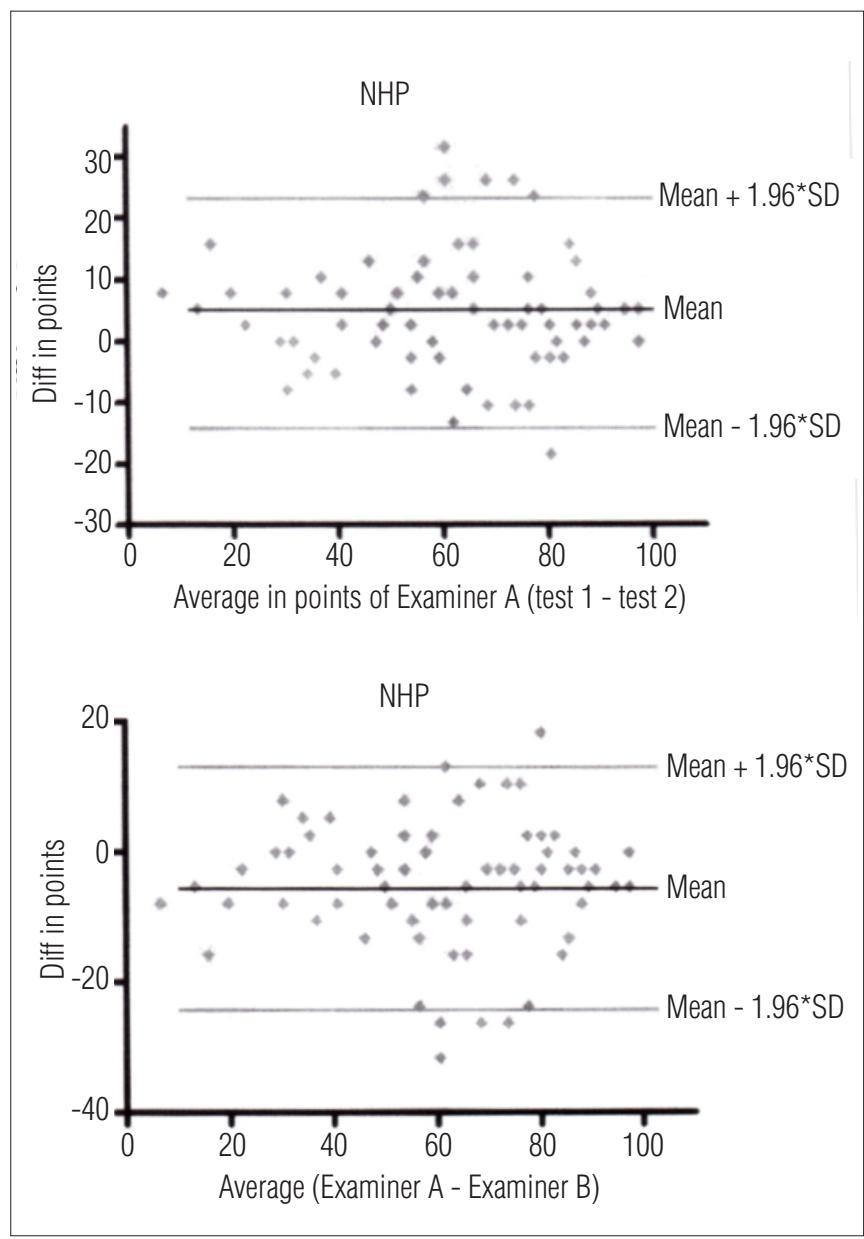

Figure 3. The Bland-Altman plots verified the agreement of the Nottingham Health Profile mean total score in relation to the test-retest and inter-rater score in individuals post-stroke ( $n=74)$, Recife, PE, Brazil, 2010.

make its application easier and less time-consuming, which enhances its clinical applicability.

The Cronbach $\alpha$ coefficient values were greater than 0.70 , indicating that the number of domains of each instrument was internally consistent, i.e. the domains were related to each other. The adequate internal consistency was also observed by Lotus Shyu, Lu and Chen ${ }^{28}$ in the analysis of the psychometric properties of the Taiwanese version of the SF-36, by comparing the first and sixth months after hospital discharge of 87 elderly individuals with stroke. Therefore, the investigated sample confirmed the possible applicability of the SF-36 at any stage of the disease. Another survey conducted in Turkey ${ }^{29}$ with 70 patients, who were receiving out-patient care after stroke, showed that both the SF-36 and the NHP achieved acceptable levels of internal consistency and demonstrated the usefulness of these measures in health services.

The ICC values for the test-retest and inter-rater reliabilities were very good for the SF-36 and excellent for the NHP. These results suggested that the number of items could affect 
the reliability of the instrument, so that domains with fewer questions are favored by lower variability and greater reliability. However, the lack of studies comparing the inter-rater reliabilities between these two instruments hinders further discussion of the present results. Boyer et al. ${ }^{30}$ confirmed the satisfactory test-retest reliability of both instruments for patients with hereditary neuromuscular diseases.

Bland-Altman plots are commonly used in comparative studies $^{31}$. However, we found few studies that compared the SF-36 and other QOL instruments using scatter plots generated by the Bland-Altman method ${ }^{32}$. In this study, in addition to the correlation analyses, the agreement levels between the total scores of the SF-36 and NHP were evaluated. The plots showed that the differences between the means were close to zero, especially for the SF-36. Thus, both instruments showed excellent test-retest agreement, indicating that the means of the first assessment were in agreement with the second in 95\% of the cases. In addition, excellent inter-rater agreement was found, confirming that the means obtained by the two raters were consistent in 95\% of the evaluations. Bland and Altman ${ }^{33}$ stressed that the agreement limits should be evaluated from clinical points of view, i.e. those differences produced by the limits should be considered clinically acceptable. Therefore, based upon the present results, it can be inferred that both instruments were shown to be suitable for clinical applications for individuals with chronic stroke.

Except for the inherent limitations of cross-sectional studies, another possible limitation of the present study could be related to the wide age range of the sample. Although the objective was not to investigate possible determinants of QOL, a stratification of the sample into two age groups (adults and elderly participants) could have clarified the interpretation of the results regarding the QOL of these individuals.

An important aspect to be considered in this study was the assessment of cognitive status as an eligibility criterion, which minimized any possible selection biases and contributed to the internal validity of the results. Moreover, the fact that the instruments were applied by trained investigators reduced the chances of interpretation error, which could influence the reliability of the results.
In general, the present study demonstrated that the health perceptions of the chronic stroke individuals were positive. We found that the common domains and the total scores of the SF-36 and NHP measured similar constructs. The higher ceiling effects observed for the NHP suggested that it was not able to differentiate individuals with different levels of QOL and, thus, demonstrated less discriminating power ${ }^{13}$. In contrast, the SF-36 demonstrated lower percentages of ceiling effects and greater discriminative capacity. For both instruments, floor effects were not observed, but the set of domains was internally consistent, and the reliability of the total scores was considered adequate, concerning both repeatability and reproducibility, although these values were slightly higher for the NHP. The scatter plot showed that the total scores of each instrument, on average, agreed between the first and second assessments and between raters.

Based upon the present findings, the generic QOL instruments SF-36 and NHP were shown to be useful for measuring the QOL of patients with chronic stroke. However, the SF-36 obtained the best results and appeared to be more suitable for evaluating the QOL of individuals during the chronic phase after stroke, which corroborates other studies that compared these instruments in individuals with chronic diseases ${ }^{14,15}$.

Considering the importance of QOL assessment in the design of therapeutic interventions, the choice of valid and reliable assessment instruments becomes crucial. QOL indicators can assist clinical practice by guiding procedures, evaluating outcomes, and even standardizing therapeutic interventions aimed at promoting both individual and public health and improving the quality of assistance to patients with stroke ${ }^{34}$. The findings of the present study not only provide clinically significant information and support to public health planning, but may also improve the cost-effectiveness of different therapeutic approaches.

\section{Acknowledgements : :}

Financial support provided by the Brazilian government funding agency Coordenação de Aperfeiçoamento de Pessoal de Nivel Superior (CAPES), Brasilia, DF, Brazil.

\section{References : : .}

1. Who. The World Health Report 2002 - Reducing risks, promoting healthy life. Geneva: World Health Organization; 2002.

2. Doyle PJ. Measuring health outcomes in stroke survivors. Arch Phys Med Rehabil. 2002;83 (12 Suppl 2):S39-43.

3. Lessa I, Bastos CAG. Epidemiology of cerebrovascular accidents of Salvador, Bahia, Brazil. Bull Pan Am Health Organ. 1983;17(3):292-303.
4. Cabral NL, Longo AL, Moro CHC, Amaral CH, Kiss HC. Epidemiologia dos acidentes cerebrovasculares em Joinville, Brasil. Arq Neuropsiquiatr. 1997;55(3-A):357-63.

5. Minelli C, Fen LF, Minelli DP. Stroke incidence, prognosis, 30-day, and 1-year case fatality rates in Matao, Brazil: a population-based prospective study. Stroke. 2007;38(11):2906-11.

6. André C, Curioni CC, Braga da Cunha C, Veras R. Progressive decline in stroke mortality in Brazil from 1980 to 1982, 1990 to 1992, and 2000 to 2002. Stroke. 2006;37(11):2784-9. 
7. Oliveira MR, Orsini M. Escalas de avaliação da qualidade de vida em pacientes brasileiros após acidente vascular encefálico. Rev Neurocienc. 2009;17(3):255-62.

8. Ciconelli RM. Medidas de avaliação de qualidade de vida. Rev Bras Reumatol. 2003; 43(2): 9-13.

9. Mota JF, Nicolato R. Qualidade de vida em sobreviventes de acidente vascular cerebral: instrumentos de avaliação e seus resultados. J Bras Psiquiatr. 2008;57(2):148-56.

10. Streiner D, Norman G. Health measurement scales - a practical guide to their development and use. New York: Oxford University Press; 2003.

11. Gonçalves CF, Oréfice JLF, Oréfice RSR, Reis FA dos. Avaliação da qualidade de vida em portadores de sequelas de acidente vascular encefálico submetidos a tratamento hidrocinesioterapêutico. Ter Man. 2009;7(32):258-62.

12. Brandão DMS, Nascimento JLS, Vianna LG. Capacidade funcional e qualidade de vida em pacientes idosos com ou sem disfagia após acidente vascular encefálico isquêmico. Rev Assoc Med Bras (1992). 2009;55(6):738-43.

13. Teixeira-Salmela LF, Magalhães LC, Souza AC, Lima MC, Lima RCM, Goulart F. Adaptação do Perfil de Saúde de Nottingham: um instrumento simples de avaliação da qualidade de vida. Cad Saúde Pública. 2004;20(4):905-14

14. Falcoz PE, Chocron S, Mercier M, Puyraveau M, Etievent JP. Comparison of the Nottinghan Health Profile and the 36-Item Health Survey Questionnaires in the cardiac surgery. Ann Thorac Surg. 2002;73(4):1222-8

15. Wann-Hansson C, Hallberg IR, Risberg B, Klevsgård R. A comparison of the Nottinghan Health Profile and Short Form 36 Health Survey in patients with chronic lower limb ischaemia in a Iongitudinal perspective. Health Qual Life Outcomes. 2004;2:9.

16. Ciconelli RM, Ferraz MB, Santos W, Meinão I, Quaresma MR. Tradução para língua portuguesa e validação do questionário genérico de avaliação da qualidade de vida SF-36 (Brasil SF-36). Rev Bras Reumatol. 1999;39(3):143-50

17. Golomb BA, Vickrey BG, Hays RD. A review of health-related quality-of-life measures in stroke. Pharmacoeconomics. 2001;19(2):155-85.

18. Lourenço RA, Veras RP. Mini-Exame do Estado Mental: características psicométricas em idosos ambulatoriais. Rev Saúde Pública. 2006;40(4):712-9.

19. Martinez MC, Paraguay AIBB, Latorre MRDO. As relações entre a satisfação com aspectos psicossociais e saúde dos trabalhadores. Rev Saúde Pública. 2004;38(1):55-61.

20. McHorney CA, Ware JEJr, Lu JFR, Sherbourne CD. The MOS 36-Item Short-Form Health Survey (Sf-36): III. Tests of data quality, scaling assumptions and reliability across diverse patient groups. Med Care. 1994;32(1):40-66.
21. Lima RCM, Teixeira-Salmela LF, Magalhães LC, Gomes-Neto M. Propriedades psicométricas da versão brasileira da Escala de Qualidade de Vida Específica para acidente vascular encefálico: aplicação do modelo Rasch. Rev Bras Fisioter. 2008;12(2):149-56.

22. Makiyama TY, Battisttella LR, Litvoc J, Martins LC. Estudo sobre a qualidade de vida de pacientes hemiplégicos por acidente vascular cerebral e de seus cuidadores. Acta Fisiátrica. 2004;11(3):106-9.

23. Cavalcante TF, Moreira RP, Araujo TL, Lopes MVO. Fatores demográficos e indicadores de risco de acidente vascular encefálico: comparação entre moradores do município de Fortaleza e 0 perfil nacional. Rev Latinoam Enferm. 2010;18(4):[6 telas].

24. Rabelo DF, Néri AL. Bem-estar subjetivo e senso de ajustamento psicológico em idosos que sofreram acidente vascular cerebral: uma revisão. Estud Psicol (Natal). 2006;11(2):169-77.

25. Kauhanen ML, Korpelainen JT, Hiltunen P, Nieminen P, Sotaniemi KA, Myllylä VV. Domains and determinants of quality of life after stroke caused by brain infarction. Arch Phys Med Rehabil. 2000;81(12):1541-6

26. Kong KH, Yang SY. Health-related quality of life among chronic stroke survivors attending a rehabilitation clinic. Singapore Med J. 2006;47(3):213-8.

27. Prieto L, Alonso J, Ferrer M, Antó JM. Are results of the SF-36 Health Survey and the Nottinghan Healh Profile Similar? A comparison in COPD patients. Quality of Life in COPD Study Group. J Clin Epidemiol. 1997;50(4):463-73.

28. Lotus Shyu YI, Lu JF, Chen ST. Psychometric testing of the SF-36 Taiwan version on older stroke patients. J Clin Nurs. 2009;18(10):1451-9

29. Unalan D, Soyuer F, Ozturk A. Should the Nottingham Health Profile or the Short Form-36 be given preference in stroke? Neurosciences (Riyadh). 2009;14(1):45-52.

30. Boyer F, Morrone I, Laffont I, Dizien 0, Etienne JC, Novella JL. Health related quality of life in people with hereditary neuromuscular diseases: an investigation of test-retest agreement with comparison between two generic questionnaires, the Nottingham health profile and short form36 items. Neuromuscul Disord. 2006;16(2):99-106.

31. Mantha S, Roizen MF, Fleisher LA, Thisted R, Foss J. Comparing methods of clinical measurement: reporting standards for Bland and Altman analysis. Anesth Analg. 2000;90(3):593-602.

32. Unalan D, Soyuer F, Ozturk A, Mistik S. Comparison of SF-36 and WHOQOL-100 in patients with stroke. Neurol India. 2008;56(4):426-32.

33. Bland JM, Altman DG. Measuring agreement in method comparison studies. Stat Methods Med Res. 1999;8(2):135-60.

34. Campos M0, Rodrigues Neto JF. Qualidade de vida: um instrumento para promoção de saúde Rev Baiana Saúde Pública. 2008;32(20):232-40. 